\title{
O PAPEL DOS INSTITUTOS CULTURAIS BRASIL-URSS NA EXPANSÃO CULTURAL SOVIÉTICA NO BRASIL
}

\author{
The Role of Brazil-USSR Cultural Institutes in the Soviet Cultural \\ Expansion in Brazil
}

\author{
Cristina Figueira SHAH \\ Pontifícia Universidade Católica do Rio de Janeiro \\ crisf.shah@gmail.com \\ https://orcid.org/0000-0003-0377-1161
}

\begin{abstract}
RESUMO: Este artigo tem como objetivo evidenciar a expansão cultural soviética no território brasileiro, especialmente no período de ditadura militar, por meio das instituições comumente conhecidas como Instituto Cultural Brasil-URSS (ICBURSS). O relacionamento entre a União Soviética e o Brasil era controverso, cheios de altos e baixos ao longo do Século XX. Porém, no período de maior repressão às ideias socialistas no Brasil, durante a ditadura militar, as relações comerciais e diplomáticas entre os dois governos foram mantidas e até expandidas. A existência dessa interação, contudo, não significa que tudo foi simples. Constrangimentos e mal entendidos entre os dois Estados eram relativamente comuns. Assim, no meio dessas relações conturbadas há uma instituição que se destaca pela sua resistência ao longo das décadas, existindo desde antes do golpe cívico-militar até o fim da União Soviética: o Instituto Cultural Brasil-URSS. Uma entidade brasileira cujo intuito era o ensino da língua russa. Desse modo averiguarei a importância dos ICBURSS do Rio de Janeiro e de São Paulo como um instrumento para a expansão da cultural soviética no Brasil. PALAVRAS-CHAVE: União Soviética; Instituto Cultural BrasilURSS; diplomacia cultural; Guerra Fria.
\end{abstract}

\begin{abstract}
This article aims to highlight the soviet cultural expansion in the Brazilian territory, especially during the period of the military dictatorship, through institutions commonly known as the Brazil-USSR Cultural Institute (ICBURSS in Portuguese). The relationship between the Soviet Union and Brazil was controversial, full of ups and downs throughout the $20^{\text {th }}$ century. Nonetheless, on the time of extreme repression of socialist ideas in Brazil, during the military dictatorship, trade and diplomatic relations among both countries were maintained and even expanded. However, the existence of this interaction does not mean that everything was simple. Constrains and misunderstandings between the two States were relatively common. Hence, in the midst of these troubled relations there is one institution
\end{abstract}


that stands out due to its resistance over the decades, existing before the rising of the civic-military coup until the end of the Soviet Union: The Brazil-USSR Cultural Institute. A Brazilian entity whose purpose was the teaching of Russian language. Thus, I will investigate the importance of the ICBURSS of Rio de Janeiro and São Paulo as an instrument for the expansion of the soviet culture in Brazil. KEYWORDS: Soviet Union; Brazil-USSR Cultural Institute; cultural diplomacy; Cold War.

\section{INTRODUÇÃO}

“Acabou, a União Soviética criada em 1922 como o primeiro Estado comunista da História agora é só isso, História" (FIM da URSS, 1991). Essas foram as palavras do jornalista Pedro Bial ao plantão da Rede Globo diretamente da União Soviética para definir aquele que foi um dos principais eventos do fim do século XX. Século esse que já tinha sido marcado por uma série de mudanças históricas. O levante do proletariado russo - que passava por crises econômicas e miséria (LOWY, 2009, p. 113) - contra o Czar que levou à ascensão política do socialismo soviético definiu boa parte dos acontecimentos da segunda metade do século.

A Revolução foi o ponto de partida para outro período histórico único no sistema internacional: a Guerra Fria entre Estados Unidos e União Soviética. Após o fim da Segunda Guerra Mundial, houve a consolidação das zonas de influência soviética na Europa Oriental como consequência das decisões tomadas na Conferência de Potsdam ${ }^{1}$ (MCMAHON, 2012, p. 32). Com a definição de lados no âmbito europeu, o próximo objetivo era influenciar o resto do mundo. Assim, ao mesmo tempo em que o mundo ocidental se distancia mais uma vez do antigo aliado na Segunda Guerra Mundial, tendo completa aversão aos bolcheviques (BEST et al., 2008, p. 174), a União Soviética se torna um fomentador de revoluções parecidas em outras regiões do mundo. Seu foco estava no chamado Terceiro Mundo ${ }^{2}$. Dessa forma, não tardou para que essa teia chegasse em solos brasileiros.

A atuação da cultura soviética no Brasil no período militar (1964-1985) é um

\footnotetext{
${ }^{1}$ De acordo com o autor Robert McMahon (2012, p. 32) a conferência de Potsdam foi realizada em 1945 logo após o fim da Segunda Guerra Mundial na Europa que tinha como um dos objetivos principais o reajuste territorial na Ásia, a participação soviética na Guerra do pacífico e, o que este presente trabalho destaca, a divisão da Alemanha e da Europa Oriental no pós guerra.

${ }^{2} \mathrm{O}$ termo "Terceiro Mundo" será utilizado ao longo do presente artigo para harmonizar com o período histórico que está sendo discutido.
} 
assunto pouco tratado. Haviam acordos comerciais, relações diplomáticas e trocas na área de educação, especialmente do lado soviético que ajudava com sua expertise na área de exatas ${ }^{3}$. Mesmo com os valores anticomunistas pregados pelos governos militares, foi possível a continuidade das ações da URSS em solo nacional, pois os custos de uma possível cisão eram altos para os brasileiros (MOTTA, 2007, p. 243). Porém, as relações intergovernamentais não se expandiam para além dos negócios em função dessa política de repressão às ideias socialistas (BLASIER, 1987, p. 36). Por esse motivo, a União Soviética precisou pensar em outros meios para se comunicar com a população brasileira em geral. Em vista disso o presente artigo pretende analisar esse outro meio, o fator cultural, mais precisamente a tentativa da URSS em promover sua cultura no Brasil através de determinadas instituições privadas de ensino da língua russa.

No meio dessas relações conturbadas entre o Brasil e a superpotência socialista, essas instituições destacam-se pela longevidade e resistência ao longo das décadas, existindo desde antes do golpe cívico-militar até o fim da União Soviética. Essas Instituições, conhecidas como Instituto Cultural Brasil-União Soviética (ICBURSS), criadas por cidadãos brasileiros (SNI, 1978, p. 1), possuindo apoio - direto ou indireto - do governo socialista. As instituições eram locais privados que tinham como objetivo o ensino da língua russa e a apresentação da língua russa aos seus frequentadores. $O$ primeiro Instituto surgiu em 1953 no Rio de Janeiro e chegou-se a ter quatorze unidades espalhadas em todo o país na década de 1980 (SNI, 1987, p.3).

Assim, com o intuito de obter as informações sobre as instituições foram entrevistadas pessoas relacionadas aos ICBURSS do Rio de Janeiro e São Paulo. Os entrevistados são tanto ex-professores e dirigentes das instituições culturais quanto ex-alunos. O objetivo é analisar as várias percepções sobre as instituições, como elas funcionavam e como era a relação dos frequentadores com o governo militar implantado na época. A segunda fonte é a análise de documentos oficiais do governo brasileiro durante seu período militar. Esses documentos mostram tanto a relação que os dois Estados (Brasil e União Soviética) possuíam quanto a visão do governo militar sobre os ICBURSS, suas atividades e seus frequentadores.

O foco principal do presente artigo está em como a União Soviética atuou na sua tentativa de expandir seu poder cultural no Brasil por meio dos Institutos Culturais Brasil-URSS das cidades do Rio de Janeiro e São Paulo. Também serão analisados avanços tecnológicos soviéticos e como eles foram peças-chave para o aumento do fluxo

\footnotetext{
${ }^{3}$ Informação retirada do site oficial do Itamaraty sobre as relações oficiais entre Brasil e Rússia. Disponível nas referências em "fontes da internet".
} 
de estudantes brasileiros (e latino-americanos no geral) nas universidades soviéticas (RUPPRECHT, 2015, p. 198). Para isso, começaremos observando as mudanças que ocorrem na política externa soviética, especialmente sobre a diplomacia cultural e o avanço tecnológico no período pós-Stalin. Depois mostraremos as relações entre a União Soviética e o Brasil em seu período de ditadura militar. Por fim, faremos uma análise sobre como essas instituições culturais possuíram um papel fundamental na difusão cultural da União Soviética para a população brasileira.

\section{A CULTURA NA POLÍTICA EXTERNA SOVIÉTICA PÓS-STALIN}

Apesar de já ser utilizada por alguns países em seus projetos de expansão - como na França em XIX (ZAMORANO, 2016, p. 170) - foi no século XX que a cultura passou a ser um elemento político amplamente utilizado na política internacional. A partir da criação da Organização das Nações Unidas para Educação, Ciência e Cultura (UNESCO) em 1945 (GOMEZ-ESCALONILLA, 1994, p. 260), os Estados perceberam que a cultura pode ser utilizada como uma forma de propagar uma visão especificamente positiva do seu país no cenário internacional. Esta imagem positiva faria com que populações das mais diversas partes do mundo simpatizassem com o Estado e assim, isto poderia evoluir para outras formas de influência. Desde então, o elemento cultural é comumente utilizado como um instrumento de expansão de poder no sistema internacional (ZAMORANO, 2016, p. 166).

Durante suas primeiras décadas de existência, especialmente no período pósSegunda Guerra chamado de "stalinismo tardio" (RUPPRECHT, 2015, p. 1), a União Soviética se manteve concentrada em suas transformações culturais internas (TRENIN, 2019, p. 70). Josef Stalin, que governou a União Soviética de maneira autocrática por quase três décadas, priorizou a implementação de um socialismo sui generis, que pausou a ideia de uma possível revolução mundial do proletariado e adotou uma política fechada em relação ao resto do mundo (RUPPRECHT, 2015, p. 22; TRENIN, 2019, p. 58). Por conseguinte, essas mudanças culturais dizem respeito principalmente na forma que o governo Stalin se relacionou com o mundo das artes.

Os artistas de uma maneira geral começaram a serem vistos como uma ferramenta do Estado, que tinham como função exaltar o estilo de vida soviético através de suas aptidões artísticas (FIGES, 2018, p. 541). Em outras palavras, produções culturais como cinema, livros, peças e músicas começaram a ser utilizados para alavancar e incutir no imaginário dos cidadãos as ideias do novo governo. Como o cientista político russo Dmitiri Trenin (2019, p. 69) em seu livro Russia afirma: 
Assim, no entanto, todas as artes eram realizadas sob forte supervisão político-ideológica. [...] Stalin, que supervisionou de perto este cenário cultural, garantiu que o povo soviético fosse tomado por um entusiasmo sincero, tornando-os em representantes de uma nova sociedade progressista $^{4}$.

A produção cultural soviética era restrita a uma certa temática e controlada para combater materiais possivelmente subversivos ao mesmo tempo que difundia os ideais soviéticos. Assim, todo o esforço de incentivar o consumo da cultura nacional se manteve ao longo do período stalinista (RUPPRECHT, 2015, p. 1; FIGES, 2018, p. 542) e não ultrapassou as fronteiras soviéticas. $\mathrm{O}$ isolacionismo praticado por Stalin fez com que essa nova cultura ficasse excluída do resto do mundo. Entretanto, após a morte de Stalin em 1953, a política externa soviética relacionada à cultura mudou drasticamente.

No governo de Nikita Khrushchev a URSS começa a olhar para a cultura como uma possibilidade política de aprimorar sua relação com outros Estados, principalmente com os do bloco capitalista (GOULD-DAVES, 2003, p. 194; RUPPRECHT, 2015, p. 74). Khrushchev começa uma modernização do país, investindo em ciência e tecnologia (FINGES, 2018, p. 617). Grandes feitos soviéticos como o seu programa espacial, que enviou satélites, animais e até o primeiro humano ao espaço, Yuri Gagarin, causaram um alvoroço internacional (CATERINA, 2020, p. 5; RUPPRECHT, 2015, p. 43). Gagarin até chegou a participar de uma turnê mundial, durante a qual visitou o Brasil em 1961, à época governado por Jânio Quadros (CATERINA, 2020, p. 6; MOTTA, 2007, p. 239). É possível dizer que esse investimento tecnológico teve frutos na influência soviética em relação ao Terceiro Mundo. Como será discutido posteriormente, muitos estudantes da África, Ásia e América Latina buscaram bolsas de estudo na URSS devido aos seus avanços tecnológicos (RUPPRECHT, 2015, p. 193).

Outro ponto importante foi a maior disposição do governo socialista em realizar negociações na área de comércio e cooperação com Estados capitalistas do Terceiro Mundo (ZUBOK, 2008, p. 428). Devidos aos acontecimentos do pós-guerra como a descolonização na África e Ásia e o declínio de governos autoritários mais ligados a potência estadunidense na América Latina (RUPPRECHT, 2015, p. 35) a nova URSS de Nikita Khrushchev viu uma oportunidade de mudar as percepções externas dessas regiões em relação ao seu Estado. Essa mudança seria viável através de políticas mais amistosas em uma coexistência pacífica, como Khrushchev disse em um discurso no Congresso soviético de 1956 (CATERINA, 2019, p. 118; RUPPRECHT, 2015, p. 22; ZUBOK, 2008,

\footnotetext{
${ }^{4}$ Tradução nossa.
} 
p. 28). É importante lembrar que essas influências internacionais eram parte importante no jogo de poder da Guerra Fria.

Na lógica da Guerra Fria entre os EUA e a URSS, apesar de muito se falar sobre as rixas acerca de segurança, armas nucleares e proxy wars - todas questões tradicionalmente associadas às disputas internacionais por poder; a influência através da cultura foi igualmente utilizada pelas superpotências (GOULD-DAVES, 2003, p. 193). Os Estados Unidos, por exemplo, usaram muito do seu dispositivo cinematográfico para se promover. Filmes como Rocky IV onde os soviéticos eram representados como maus, trapaceiros e traiçoeiros, os grandes vilões que os mocinhos estadunidenses precisavam derrotar, eram comuns durante a Guerra Fria.

Portanto, os dispositivos culturais nacionais (estadunidenses e soviéticos) eram utilizados como uma forma de angariar simpatia da sociedade civil de Estados terceiros e, assim, conseguir expandir-se de maneira mais concreta (MORTAZAVI; MOHAGHEGHNIA; REZAKHANI, 2018, p. 251) no âmbito da política ou da economia. Logo, a União Soviética se utilizou dessas táticas culturais para expandir sua zona de influência. Os valores da cultura seriam espalhados pela população através do aprendizado da língua, das artes - englobando também obras cinematográficas e musicais - e ideias no contexto de conseguir hearts and minds da sociedade (EINBINDER, 2013, p. 8; GOULDDAVES, 2003, p. 195). Essa disputa cultural constituiu em parte fundamental da Guerra Fria. A difusão de conhecimento para outras sociedades virou uma forma de conseguir poder (GUZZINI, 2005, p. 499) em regiões onde a União soviética não possuía controle militar. Por esse motivo os Institutos Culturais foram instrumentalizados a seu favor.

Como consequência dessa necessidade de expandir suas ideias, as duas superpotências começam a empregar a diplomacia cultural na sua política externa. $O$ conceito de diplomacia cultural pode ser observado a partir de diferentes ângulos. Segundo a UNESCO sua definição seria "uma forma de soft power que se esforça para promover o intercâmbio de visões e ideias, promover conhecimento de outras culturas e criar pontes entre essas comunidades"5. Por sua vez o soft power, termo cunhado pelo acadêmico Joseph Nye, é definido como "a habilidade de moldar as preferências dos outros"6 (2004, p. 5). Esse tipo de poder é diferente daquele implementado até então, o hard power. O hard power seria formar essas preferências de outros atores através de métodos coercitivos (NYE, 2004, p. 5).

\footnotetext{
${ }^{5}$ Tradução nossa.

${ }^{6}$ Tradução nossa
} 
Apesar dessas formas mais brandas de se fazer política existirem, esses métodos coercitivos dominaram o cenário internacional durante muito tempo. Um exemplo de hard power seriam os conflitos armados entre dois ou mais Estados. O soft power, por sua vez, está mais relacionado ao poder cooptivo ${ }^{7}$, que visa atrair os outros atores a partir dos valores e habilidades que seu Estado apresenta (NYE, 2004, p. 7). Assim, uma das possíveis maneiras de influenciar outros Estados é através da cultura. Porém, mesmo com a definição de diplomacia cultural baseada nos argumentos de Joseph Nye sendo a mais utilizada, há outras maneiras de se pensar o tema.

O acadêmico Cesar Villanueva, por exemplo, pensa a diplomacia cultural através da construção social de discursos (2007, p. 36). O discurso que um Estado faz sobre si mesmo, pode influenciar a maneira que os outros o enxergam no sistema internacional. O presente artigo usará, no entanto, a definição de Manuela Aguilar sobre diplomacia cultural. Para Aguilar, a diplomacia cultural seria "a maneira que um governo se apresenta para a população de outros países que ajudaria esse governo a atingir seus objetivos de política externa" (1996, p. 8 apud VILLANUEVA, 2007, p. 38) ${ }^{8}$. No caso aqui estudado, isto seria apresentar aos brasileiros somente o lado bom e moderno da Administração soviética, fazendo-os apreciar o governo (não necessariamente a parte ideológica do mesmo).

Com esse entendimento sobre os conceitos de diplomacia cultural é possível pensar nos Institutos e Uniões Culturais, que eram possivelmente utilizados como um mecanismo para contornar a imagem da cultura soviética em um país tão avesso à mesma. $\mathrm{O}$ fato dessas instituições não fazerem parte do governo soviético facilitou a sua existência durante o regime militar. Porém, por ser um espaço de interação e aprendizado sobre a língua, as músicas e outros tipos de arte (EINBINDER, 2013, p. 8) do regime soviético, era de interesse do governo socialista ajudar na expansão dos institutos. Ajuda essa que resultou no aumento no número de cidadãos brasileiros engajados com a União Soviética, especialmente na década de 1980. Por exemplo, com um maior fluxo de brasileiros querendo visitar o Estado socialista ou mesmo almejando completar seus estudos em Moscou.

Dessa forma, a URSS usou o ensino da língua russa e da cultura soviética que o Instituto promovia. A cultura se transformava aos poucos em uma forma alternativa de competição entre União Soviética e Estados Unidos, menos custosa e menos danosa

\footnotetext{
7 Tradução nossa do termo cooptive power de Joseph Nye.

${ }^{8}$ Tradução nossa.
} 
de expandir seu sistema político para o resto do mundo (GOULD-DAVES, 2003, p. 195). Para Gould-Daves a vitória na Guerra Fria seria baseada na conversão de pessoas e Estados para o seu escopo (2003, p. 196). Desse modo, a União Soviética começou a interagir com alguns países da esfera de influência capitalista. E, consequentemente, não demorou muito para essa tentativa de expansão chegasse ao Brasil. Então, qual foi a reação do governo brasileiro?

\section{AS RELAÇÕES BRASIL-URSS DURANTE O REGIME MILITAR}

Nas décadas posteriores ao fim da Segunda Guerra Mundial os Estados Unidos se consolidaram como o influenciador externo principal do território brasileiro no contexto da Guerra Fria. Isto posto, como a União Soviética conseguiu se relacionar com o Brasil?

A política externa mais aberta de Khrushchev focava bastante no Terceiro Mundo. A URSS via nesses países a possibilidade de conseguir aliados e assim, adquirir vantagem na disputa por influência com o Ocidente (MCMAHON, 2012, p. 78). Na região da América Latina, o Brasil era visto como um ator estratégico tanto pelos soviéticos quanto pelos estadunidenses na disputa de influência da Guerra Fria. Como Cole Blasier discorre em seu The Giant's Rival: the USSR and Latin America, fatores como a grande população, o vasto e diversificado território, suas exportações bem como sua influência no resto dos países do continente latino-americano aguçavam os interesses soviéticos em cooperar com o governo brasileiro (1987, p. 32). Entretanto, a relação entre a superpotência socialista e o país latino americano foi inconstante ao longo de todo o período da Guerra Fria (MOTTA, 2007, p. 239). Desde a Revolução de 1917, o Brasil se dividia entre momentos de maior interação e de maior afastamento com os governos soviéticos. O Brasil reconheceu a URSS pela primeira vez em 1945, mas, dois anos depois cortou laços com o país pela primeira vez (BLASIER, 1987, p. 33).

Entretanto, nas décadas de 1950 e 1960 (até o golpe cívico-militar) as interações entre os dois países se mantinham fortes. O Brasil, assim como muitos países do Terceiro Mundo na primeira metade do século XX, buscava a construção de sua autonomia estatal (REIS, 2005, p. 18). O Estado brasileiro nesta época procurava se relacionar com os demais através de seus próprios interesses. Com governantes mais ligados ao nacionalismo e aos objetivos desenvolvimentistas como Kubitscheck, Quadros e Goulart (RUPPRETCH, 2011, p. 507), uma oportunidade de negociação com o bloco socialista se abriu. A retomada das relações foi rápida, e as perspectivas soviéticas estavam boas. Porém, se Moscou estava feliz, não poderia dizer-se o mesmo de Washington. 
Os Estados Unidos, pelos mesmos motivos dos soviéticos, também queriam possuir parcerias com o grande país latino-americano. Nessa disputa a superpotência ocidental possuía a vantagem. Por esse motivo, eles não deixariam que um Estado tão estratégico se aproximasse em tal grau dos países socialistas (BLASIER, 1987, p. 34). Além disso, apesar dos três últimos governos democraticamente eleitos no Brasil terem sido mais condizentes aos ideais socialistas - principalmente o governo de João Goulart - (RUPPRECHT, 2011, p. 509), o governo estadunidense ainda tinha enorme influência dentro da sociedade brasileira. As elites conservadoras eram contrárias as atitudes de Goulart e seus ideais políticos mais voltados para a esquerda (GONÇALVES; MIYAMOTO, 1993, p. 213). Havia também um medo existente devido ao sucesso da Revolução Cubana de 1959. Acreditavam-se na possibilidade de algo semelhante ocorrer no Brasil (CATERINA, 2019, p. 261).

À vista disso, ao mesmo tempo em que a União Soviética se esforça para ampliar seu mecanismo estatal de difusão cultural, suas intenções foram barradas pelo golpe cívico-militar que ocorreu em 1964 com a ajuda dos Estados Unidos. O golpe instaurou um regime militar, em um primeiro momento apoiado pelo Estados Unidos, e contra qualquer princípio socialista (MOTTA, 2007, p. 240). Por exemplo, o governo militar de Castelo Branco cortou relações com os jovens revolucionários cubanos (BLASIER, 1987, p. 34) e não as retomou até a redemocratização brasileira em $1986^{9}$. Desse modo, para entender melhor o modus operandi da atuação soviética durante a Guerra Fria é necessário analisar os dois tipos de relação existentes entre a URSS e o Brasil neste período.

A primeira delas é a relação comercial, oficializada através de acordos bilaterais. No governo do general Médici as relações tecnológicas e comerciais Brasil-União Soviética estavam em uma boa fase, sendo o ano de 1972 o ano recorde nas relações comerciais entre URSS e o Brasil (BLASIER, 1987, p. 35). Esse fato contrasta com a grande repressão anticomunista que o próprio general fomentava no país na mesma época (BRANDS, 2010, p. 131) O período de déténte ${ }^{10}$ tornou a atmosfera do sistema internacional mais favorável à cooperação entre países politicamente tão distintos quanto União Soviética e Brasil.

\footnotetext{
${ }^{9}$ Informação retirada do site oficial do Itamaraty sobre as relações oficiais entre Brasil e Cuba. Disponível nas referências "fontes da internet".

${ }^{10}$ Segundo a definição de Robert McMahon, se refere ao período de relaxamento de tensões, tornando as relações entre Estados Unidos e União Soviética mais estáveis e cooperativas (2012, p. 140).
} 
Com o ambiente amigável entre as duas nações, há o estabelecimento de um escritório Soviético no Rio de Janeiro para fins comerciais bem como o Acordo de Comércio e Pagamentos entre os dois Estados, acontecimentos que ocorreram no ano de 1972 (SOARES, 1975, p. 218-219). Ao longo da década de 1980, durante o governo do General Figueiredo, a União Soviética também exporta sua tecnologia e inteligência na área da engenharia. A superpotência investiu e auxiliou na criação de usinas elétricas em território nacional (GERHARD, 2015, p. 43). Essas boas relações comerciais no âmbito interestatal constituíram um dos passos utilizados para que a União Soviética viesse a obter alguma influência sobre o Estado brasileiro - mesmo que muito pouca.

Porém, não foi na esfera governamental que os ideais socialistas soviéticos foram difundidos no território nacional: a tentativa de expansão desses ideais foi feita a partir da sociedade civil através da diplomacia cultural citada anteriormente. A tentativa de difusão da cultura soviética como um instrumento para atrair a sociedade civil e fazê-la simpatizar com o Estado socialista foi utilizada de maneira indireta em solo brasileiro. A cultura soviética começou a ser exportada para o Brasil por meio de suas artes como ballet, pinturas e filmes (GOULD-DAVES, 2003, p. 208; TRENIN, 2019, p. 106). Esse intercâmbio cultural começou a ser propagado na década de 1950, quando as relações estavam sendo retomadas depois de anos de cisão (BLASIER, 1987, p. 33; MOTTA, 2007, p. 239).

Nesse cenário, em 1953, foi aberto pela primeira vez o Instituto Cultural Brasil União Soviética no Rio de Janeiro, então capital federal. Anos mais tarde, em 1960, foi inaugurado a segunda instituição, denominada União Cultural Brasil-URSS, em São Paulo capital (SNI, 1984, p. 3). A trajetória histórica dos ICBURSS e UCBURSS pesquisados, com todos os seus altos e baixos, marca a disputa de poder cultural existente na lógica da Guerra Fria. Apesar da maior proximidade com os Estados Unidos, a atuação da União Soviética em solo brasileiro também deve ser considerada e, consequentemente, mais estudada. Desse modo, é importante prestar uma atenção nos motivos pelos quais essas instituições, mesmo não sendo oficialmente coordenadas pelo Kremlin, são tão importantes para entender a propagação da cultura soviética em solo brasileiro.

\section{OS INSTITUTOS: SUA HISTÓRIA E SUA FUNÇÃO}

Pode-se dizer que essas instituições de ensino da língua russa acabaram se transformando no principal instrumento utilizado por ela para angariar adeptos da sociedade civil brasileira aos ideais soviéticos. Os anos passaram, o golpe de 1964 
foi instaurado e o presidente João Goulart teve que se exilar. Mesmo com todos esses fatores agindo contra União Soviética e suas possíveis ambições, as relações oficiais e os Institutos continuaram existindo e realizando seus trabalhos, apesar de existir um medo constante de uma possível reação negativa dos militares brasileiros (MOTTA, 2007, p. 242). Embora não fosse oficialmente ilegal (as ações dos institutos eram legalizadas perante a lei), relatos de alguns frequentadores dos Institutos de São Paulo e do Rio de Janeiro revelam que o estudo da língua russa era mais do que reprovado, e que passaram por alguns constrangimentos por estarem associados às Instituições, especialmente nos primeiros anos da ditadura ${ }^{11}$.

A partir das histórias contadas por ex-professores, dirigentes e alunos é possível analisar as várias percepções sobre o instituto, como eles funcionavam (como era a vida cotidiana) e como era a relação dos frequentadores com o governo militar implantado na época. Junto às entrevistas foram analisados documentos oficiais do governo brasileiro durante seu período militar, como aqueles escritos pelo Serviço Nacional de Informações, que também são de extrema importância para mostrar a relação das instituições de ensino da língua russa com o governo soviético. Desse modo, qual a importância de investigar os Institutos Culturais Brasil-URSS? Por que especificamente os Institutos do Rio de Janeiro e São Paulo? Qual foi o seu papel nessa tentativa de expansão soviética por meios não coercitivos?

Antes, é válido ter em mente que, segundo o Secretário-Geral do Instituto de São Paulo, entrevistado pela autora deste artigo, os nomes dos Institutos eram dados de acordo com o nome das Instituições culturais estadunidenses que existiam em cada cidade. Essa semelhança nominal era uma forma de blindar as instituições apoiadas pela União Soviética de possíveis repressões. Uma vez que as instituições estadunidenses eram permitidas, a União Soviética também reivindicava legitimidade para sua existência. Por esse motivo os nomes das Instituições do Rio de Janeiro e São Paulo diferem; sendo Instituto BrasilURSS (ICBURSS) na primeira e União Cultural Brasil URSS (UCBURSS) na última.

Assim sendo, é importante ressaltar os motivos dos Institutos do Rio de Janeiro e São Paulo serem os escolhidos para a análise. São Paulo e Rio de Janeiro são vistas como as cidades mais importantes do Brasil, tanto no âmbito econômico quanto no cultural. Idealizado por intelectuais da esquerda brasileira (SNI, 1978, p. 1), a criação do Instituto

\footnotetext{
${ }^{11}$ Em 1972 os diretores do ICBURSS foram processados por uso de propaganda subversiva. A investigação foi arquivada por falta de provas no mesmo ano. O Serviço Nacional de Informações possui um documento especial sobre o assunto que será disponibilizado na seção "Documentos oficiais, relatórios e estudos".
} 
Brasil URSS teve como objetivo oficial o ensino da língua russa para brasileiros. O primeiro dos Institutos fundados foi o ICBURSS do Rio de Janeiro em 1953, que passou a funcionar como sede desse mecanismo no país. Por sua vez, a União Cultural BrasilURSS de São Paulo abriu suas portas oficialmente no ano de 1960 (SNI, 1984, p. 3) sendo o segundo a entrar em atividade. Os estados são dois dos mais populosos de todo o território nacional (IBGE, 2020). Ao lado da Instituição de Porto Alegre, essas foram as únicas três associações em território brasileiro até a década de 1980 segundo os próprios relatos do SNI (SNI, 1984, p. 2). Devido ao fato de que, até 1960, o Rio de Janeiro foi a Capital Federal do Brasil e que São Paulo já era o centro financeiro do país, com um grande fluxo de migrantes estrangeiros, suas localizações eram estratégicas. A maioria dos eventos culturais relacionados com a URSS eram realizados nos dois estados.

Por sua vez, são inúmeros os fatores que ratificam a importância dos ICBURSS como um instrumento de expansão da cultura soviética no Brasil. Começarei mostrando o porquê essas instituições, tão pequenas se analisadas em uma perspectiva macro, devem ser estudadas. Devido à resistência das autoridades brasileiras em relação a qualquer atividade soviética no Brasil (MOTTA, 2007, p. 240), os soviéticos tiveram que adentrar e difundir sua cultura de maneira mais discreta. Desse modo, os Institutos além de ensinar russo, ofereciam uma nova visão sobre a União Soviética. Ela deixava de ser vista somente como um inimigo e passava a ser vista com interesse por aqueles que estavam relacionados com os ICBURSS de alguma forma. Além disso, segundo o Ex-Secretário Geral da União de São Paulo, todas essas instituições culturais de ensino estavam conectadas a uma matriz soviética. Essa matriz era a Casa da Amizade com os povos estrangeiros de Moscou que não tinha controle sobre as instituições, mas servia como um facilitador da ajuda soviética para com os ICBURSS. Posto isto, é válido dizer que os institutos fazem sim parte de um projeto soviético muito maior e devem receber a devida atenção.

A aproximação linguística que as instituições trouxeram entre Brasil e União Soviética também deve ser discutida. Os ICBURSS eram a principal fonte de aprendizado da língua russa (MOTTA, 2007, p. 239) durante o período militar. Ter cada vez mais brasileiros falando o idioma russo - língua oficial da URSS - aumentava indiretamente a relevância da cultura soviética em território nacional. As instituições do Rio de Janeiro e de São Paulo formaram inúmeros alunos fluentes em russo ao longo de toda sua existência. Em muitos dos casos os alunos formados acabavam permanecendo na rotina dos institutos, como professores no Rio de Janeiro - e professores voluntários em São 
Paulo $^{12}$. Isso aconteceu com todos os entrevistados para a presente pesquisa.

Os dirigentes das instituições também eram utilizados como intérpretes toda vez que uma personalidade soviética vinha ao Brasil. Por exemplo, se a seleção soviética vinha jogar contra a seleção brasileira ou o ballet Bolshoi fazia apresentações, esses dirigentes eram chamados. Isso era tanto uma forma de propaganda para as instituições obterem mais alunos como uma forma de blindar os ICBURSS pois, uma vez que o ensino da língua russa não era altamente propagado em território nacional, se fazia necessário manter o instituto para continuar possuindo intérpretes e tradutores de português-russo.

$\mathrm{Na}$ década de 1980, o aumento do número de alunos levou à criação dessas Instituições culturais. Em tempos áureos, o número de franquias em território brasileiro chegou a quatorze, sendo algumas apoiadas diretamente pelo governo da URSS (SNI, 1987, p. 1). Foi nesse mesmo período que os institutos começaram a oferecer outros tipos de atividades ${ }^{13}$. Além do aprendizado da língua russa, esses institutos também exerciam outras funções. Os entrevistados alegaram que o UCBURSS de São Paulo serviu como espaço cultural para exposições de arte e fotografia sobre a União Soviética; realizava tardes de exibição de filmes onde eram rodados longas-metragens da União Soviética e de países do Leste Europeu. ${ }^{14}$ Também haviam campeonatos esporádicos de xadrez. Todo o material necessário para ambos os eventos era cedido pela própria União Soviética. Segundo documentos oficias do Serviço Nacional de Informações, essas atividades de cunho cultural também eram incentivadas e fomentadas no ICBURSS do Rio de Janeiro (SNI, 1978, p. 3). Além disso, tanto o UCBURSS quanto o ICBURSS publicavam conteúdos próprios. Exemplos desses conteúdos são as publicações mensais dos boletins informativos Drujba (Instituto do Rio de Janeiro) e Soyuznik (União de São Paulo).

Por fim, a atividade mais importante seria o envio de estudantes brasileiros para as universidades soviéticas. As instituições possuíam um projeto de intercâmbio para os alunos brasileiros realizarem sua graduação em Moscou, mais especificamente nas Universidade Amizade dos Povos Patrice Lumumba (UAPPL) e o Instituto Pushkin, ambos em Moscou. Criada para graduar estudantes de países do Terceiro Mundo (KATSAKIORIS, 2019, p. 281) a Universidade Patrice Lumumba também passou a constituir um recurso importante no fortalecimento dessa ligação Brasil-URSS. Por sua vez, o Instituto Pushkin é uma Universidade que tem como objetivo graduar futuros professores de língua russa. Ela

\footnotetext{
${ }^{12}$ Entrevista com o ex-professor da UCBURSS, dia 09/06/20, São Paulo.

${ }^{13}$ Entrevista com o ex-Secretário Geral do UCBURRS, dia 19/06/2020, São Paulo.

${ }^{14}$ Entrevista com o ex-Secretário Geral do UCBURRS, dia 19/06/2020, São Paulo.
} 
visava o intercâmbio cultural entre soviéticos e o resto do mundo. Segundo os professores entrevistados as bolsas referiam-se aos estudos como também ao custo de vida na União Soviética, cobrindo despesas com alimentação, materiais de estudo e lazer.

O objetivo principal da União Soviética ao conceder essas bolsas não era mais o de doutrinar seus estudantes, como na época de Stalin, mas sim mostrar uma nova União Soviética, moderna e tecnológica que poderia oferecer qualificações tão boas quanto qualquer país Ocidental (RUPPRECHT, 2015, p. 198). O sistema de bolsas soviético pode ser considerado o principal mecanismo de diplomacia cultural. Os entrevistados das duas instituições (ICBURSS E UCBURSS) afirmaram que muitos alunos entravam nas Instituições Culturais com a intenção de cursar faculdade na URSS, especialmente nas áreas de tecnologia e engenharia. Esse fato per se mostra o sucesso da União Soviética no seu poder cooptivo. A modernização, principalmente vinda do programa espacial, rendeu os frutos tão desejados. O desejo de jovens brasileiros em estudar em terras soviéticas traz um novo tipo de poder e influência à URSS no cenário internacional, um tipo de soft power. Através da educação que os estudantes recebiam e do tempo em que permaneciam na URSS, eles - teoricamente - gostariam da vida no país socialista e voltariam para suas casas com boas impressões (RUPPRECHT, 2015, p. 194).

Portanto, a partir dos relatos dos ex-professores, dirigentes e alunos e da análise de documentos oficiais do governo militar, é possível constatar a importância dos Institutos Culturais Brasil União Soviética. Importância essa que vai além do território brasileiro, visto que os Institutos eram interligados de alguma forma com Moscou. Desse modo, os ICBURSS tiveram um papel de destaque na tentativa soviética de transformar a percepção da população brasileira em relação ao Estado socialista. Com a dissolução da URSS em 1991 ocorre o fim de todos os Institutos da maneira que existiam. Porém, ao menos nas duas cidades recortadas no presente artigo, Rio de janeiro e São Paulo, emergiram centros de ensino da língua russa que ainda deixam vivas as memórias do Instituto. Essa reminiscência soviética se dá através dos materiais utilizados pelos alunos e pelas pessoas que eram ligadas ao instituto e que permaneceram nos novos centros contando assim suas histórias para as novas gerações.

\section{CONSIDERAÇÕES FINAIS}

O presente artigo analisou a importância dos institutos culturais Brasil-URSS do Rio de Janeiro e São Paulo na expansão da União Soviética durante a lógica da Guerra Fria. Assim, mesmo o Brasil passando por um governo militar que foi inicialmente 
apoiado pelos Estados Unidos e perdurou vinte e um anos, o governo soviético conseguiu encontrar seus meios de sustentar uma certa influência em determinada parte da população brasileira. Durante os anos 1960 e 1970 a pura existência e manutenção dos Institutos já era uma vitória para a URSS.

A diplomacia cultural soviética, produzida essencialmente através da disseminação da língua russa, na exposição de mostras artísticas - como o ballet Bolshoi - e nos seus avanços tecnológicos. Todos esses dispositivos culturais soviéticos eram direta e indiretamente fomentados no ICBURSS e no UCBURSS assim como pelas outras filiais espalhadas pelo Brasil. A concessão de bolsas na área de ciências, tecnologia e letras para universidades moscovitas, que eram em parte providas através das Instituições, também auxiliaram na expansão da simpatia dos leigos e não afiliados a partidos políticos, para com a União Soviética. Desse modo, é possível constatar que, mesmo não sendo instituições oficiais do regime socialista, as atividades realizadas nas mesmas ajudaram a difundir a cultura soviética na sociedade civil.

A redemocratização brasileira, as políticas de Glasnost e Perestroika, até a queda da União Soviética impactaram os Institutos Brasil-URSS de maneiras diferentes. Focando na última mudança citada, é possível retomar a fala que abre o presente artigo. Apesar da União Soviética ter virado passado, como disse Pedro Bial na citação que abre o presente artigo, o mesmo não se deu com a cultura. Mesmo com essas mudanças, será que ainda é possível observar o poder de atração cultural soviético existente no século passado sendo aplicado nos atuais centros de ensino da língua russa tanto no Rio de Janeiro quanto em São Paulo? Com isso, surge a indagação se o fim da União Soviética e o fim dos Institutos Culturais Brasil-URSS culminou com o fim da sua História. Talvez não tenha sido um fim, mas sim um ponto de inflexão.

\section{AGRADECIMENTOS}

Gostaria de agradecer todos que me auxiliaram na execução deste artigo. Um agradecimento especial para a Prof. Doc. Renata Summa, por ter me incentivado a produzir a pesquisa e expô-la no I Encontro Internacional de Estudos Poloneses, além de ter me ajudado em todas as etapas do projeto. Também gostaria de agradecer os meus queridos entrevistados, que compartilharam suas memórias pessoais em prol da confecção dessa pesquisa. Por fim, gostaria de agradecer todos aqueles que leram, corrigiram e aprimoraram minha pesquisa, tornando-a mais completa. 


\section{REFERÊNCIAS:}

BEST, Antony.; HANHIMAKI, Jussi M.; MAIOLO, Joseph A.; SCHULZE, Kirsten E. International history of the Twentieth Century and Beyond. 2. ed. New York: Routledge, 2008. p. 172- 176.

BLASIER, Cole. The Giant's Rival: the USSR and Latin America. Ed. rev., Pittsburgh: University of Pittsburgh Press, 1987. p. 3-76.

BRANDS, Hal. Latin America's Cold War. Cambridge: Harvard University Press, 2010, p. 119-150.

CATERINA, Gianfranco. Gagarin in Brazil: reassessing the terms of the Cold War domestic debate in 1961. Rev. Bras. Polit. Int., Brasília, v. 63, n.1, p. 1-16, 09 mar. 2020.

CATERINA, Gianfranco. Um Grande Oceano: Brasil e União Soviética atravessando a Guerra Fria (1947-1985). 426 f. Tese (Doutorado em História, política e Bens Culturais) - Centro de Pesquisa e Documentação de História Contemporânea do Brasil, Fundação Getúlio Vargas, Rio de Janeiro, 2019.

EINBINDER, Mary. Cultural Diplomacy: Harmonizing International Relations through music. 72 f. Dissertação (Mestrado em Artes) - Gallatin School of Individualized Studies, New York University, New York, 2013.

FIGES, Orlando. Uma história cultural da Rússia. Tradução de Maria Beatriz de Medina. 2. ed. Rio de Janeiro: Record, 2018. p. 525- 628.

GEHARD, Philipp. Oportunismo ideológico? As relações econômicas entre a União Soviética e a ditadura. Revista Espaço Acadêmico, v. 15, n 175, dez. 2015. p. 39-47.

GOMES-ESCALONILLA, Lorenzo Delgado. El factor cultural en las relaciones internacionales: una aproximación a su análisis histórico. Hispania: Revista española de historia, v. 54, n. 186, p. 257-278, 1994.

GONÇALVES, Williams da Silva; MIYAMOTO, Shiguenoli. Os militares na política externa brasileira: 1964-1984. Revista Estudos Históricos, Rio de Janeiro, v. 6, n. 12, p, 211-246, dez. 1993.

GOULD-DAVES, Nigel. The logic of Cultural Diplomacy. Massachusetts: Blackwell Publishing, 2003. p. 193- 214.

GUZZINI, Stefano. The Concepst of Power: A Constructivist Analysis. Millennium: Journal of International Studies, Londres, v. 33, n. 3, p. 495 - 508, 2005. 
KATSAKIORIS, Constantin. The Lumumba University in Moscow: higher education for the Soviet-Third World alliance, 1960-1991. Cambridge: Cambridge University Press, 2019. p. 281-300.

LOWY, MICHAEL (org.). Revoluções. São Paulo: Boitempo, 2009, p. 111- 121.

MCMAHON, Robert J. Guerra Fria. Porto Alegre: L\&PM, 2012.

MOHAGHEGHNIA, Hamed.; MORTAZAVI, Gholamreza.; REZAKHANI, Jafar. The role of Cultural Power and its influence on Global Developments. Journal of History Culture and Art Research, [S.1.], v. 7, n. 1, p. 242-260, mar. 2018.

MOTTA, Rodrigo. O Perigo é Vermelho e vem de Fora: O Brasil e a URSS. Locus: Revista de História, Juiz de Fora, v. 13, n. 2, p. 229-246, 2007.

NYE, Joseph. Soft Power. Nova York: Publicaffairs, 2004, p. 1-25.

REIS, Daniel Aarão. Ditadura Militar, esquerdas e sociedade. Rio de Janeiro: Jorge Zahar Editor Ltda, 2005.

RUPPRECHT, Tobias. Socialist high modernity and global stagnation: a shared history of Brazil and the Soviet Union during the Cold War. Journal of Global History, Cambridge, v. 6 , n. 3, p. 505-528, nov. 2011.

RUPPRECHT, Tobias. Soviet Internationalism After Stalin: Interaction and Exchange between the USSR and Latin America during the Cold War. Cambridge: Cambridge University Press, 2015.

SOARES, Guido. Contratos Internacionais e Comércio Exterior com a URSS. Revista Da Faculdade De Direito, Universidade De São Paulo, São Paulo, v. 70, 1 jan. 1975.

TRENIN, Dmitri. Russia. Cambridge: Polity Press, 2019, p. 58-121.

VILLANUEVA, Cesar. Representing Cultural Diplomacy: Soft power, cosmopolitan constructivism and nation branding in Mexico and Sweden. Växjö: Växjö University Press, 2007, p. 31-60.

ZAMORANO, Mariano. Reframing Cultural Diplomacy: The instrumentalization of culture under the Soft Power Theory. Linkoping: Linkoping University Eletronic Press, 2016.

ZUBOK, Vladislav. The Soviet Union and détente of the 1970s. Cold War History, v. 8, n. 4 , p. $427-447,10$ out. 2008. 


\section{DOCUMENTOS OFICIAIS DO ARQUIVO NACIONAL:}

SNI, 1972. Serviço Nacional de informações. Instituto Cultural Brasil-URSS.

SNI, 1978. Serviço Nacional de informações. Instituto Cultural Brasil- União Soviética.

SNI, 1984. Serviço Nacional de informações. Proliferação dos "Institutos Culturais Brasil URSS" (ICBURSS) com o apoio da Embaixada da União Soviética.

SNI, 1987. Serviço nacional de informações. Entidades Culturais de Intercâmbio entre o Brasil e a União Soviética - Endereços.

\section{FONTES DA INTERNET:}

FIM da URSS. Plantão da Globo. Rio de Janeiro: Rede Globo, 25 dez. 1991. Programa de televisão. Disponível em: <https://www.youtube.com/watch?v=1XY7qWbdXe0>. Acesso em 14 ago. 2020.

IBGE - INSTITUTO BRASILEIRO DE GEOGRAFIA E ESTATÍSTICA. Estados mais populosos. Disponível em: <https://cnae.ibge.gov.br/en/component/content/article/977a12/7a12vocesabia/curiosidades/1632-estados-mais-populosos.html $>$. Acesso em 07 jun. 2020.

MINISTÉRIO DAS RELAÇÕES EXTERIORES, 2018. República de Cuba. Disponível em: <http://www.itamaraty.gov.br/pt-BR/ficha-pais/5085-republica-de-cuba>. Acesso em 31 jul. 2020.

MINISTÉRIO DAS RELAÇÕES EXTERIORES, 2019. Federação da Rússia. Disponível em: <http://www.itamaraty.gov.br/pt-BR/ficha-pais/5587-federacao-da-russia $>$. Acesso em 14 ago. 2020.

UNESCO. The Soft Power of Culture. Disponível em: <http://en.unesco.org/themes/ intercultural-dialogue $>$. Acesso em 06 maio 2020.

URSS chega ao fim após renúncia de Mikhail Gorbachev. Jornal Nacional - Arquivo $J N$. Rio de Janeiro: Rede Globo, 25 dez. 2010. Programa de televisão. Disponível em: $<$ http://g1.globo.com/jornal-nacional/noticia/2010/12/arquivo-jn-urss-chega-ao-fimapos-renuncia-de-mikhail-gorbachev.html>. Acesso em 22 maio 2020. 


\section{ENTREVISTAS:}

\begin{tabular}{|c|c|c|c|}
\hline Posição do entrevistado & Contexto da entrevista & Data & Idioma \\
\hline $\begin{array}{c}\text { Ex-professora do Instituto Cultural } \\
\text { Brasil-URSS do Rio de Janeiro }\end{array}$ & Pessoalmente & $29 / 10 / 2019$ & Português \\
\hline $\begin{array}{c}\text { Ex-professor da União Cultural } \\
\text { Brasil URSS de São Paulo 1 }\end{array}$ & Por e-mail & $04 / 11 / 2019$ & Português \\
\hline $\begin{array}{c}\text { Ex-professor da União Cultural } \\
\text { Brasil-URSS de São Paulo 2 }\end{array}$ & Por telefone & $09 / 06 / 2020$ & Português \\
\hline $\begin{array}{c}\text { Ex-secretário geral da União Cultural } \\
\text { Brasil-URSS de São Paulo }\end{array}$ & Por telefone & $19 / 06 / 2020$ & Português \\
\hline $\begin{array}{c}\text { Ex-professor da União Cultural } \\
\text { Brasil-URSS de São Paulo 3 }\end{array}$ & Por e-mail & $13 / 07 / 2020$ & Português \\
\hline
\end{tabular}

